\title{
Who obtains abortion in Georgia and why?
}

This article was published in the following Dove Press journal:

International Journal of Women's Health

\author{
Ekaterine Pestvenidze \\ Babill Stray-Pedersen \\ Institute of Clinical Medicine, \\ Rikshospitalet, Division of Women \\ and Children, University of Oslo, \\ Oslo, Norway
}

Purpose: While induced abortion practices are common in Georgia, the sociodemographic subgroups of women predominantly affected by abortion and their leading motives have not yet been explored. The study aims to understand differentials in women undergoing abortion according to background characteristics and get insight into their reasons for availing of abortion services.

Materials and methods: We analyzed the data on 2,054 abortions from the Georgian Reproductive Health Survey 2010. We computed an abortion index (AI) to identify the subgroups of women with the highest relative abortion rates. We performed descriptive analysis of the reasons for pregnancy termination and assessed the statistical significance of differences in proportions using the chi-squared test. We applied multivariate binary logistic regression analyses to study the sociodemographic predictors of the four leading reasons for abortion.

Results: In Georgia, women seeking abortion were predominantly those with two or more children (AI 1.9-2.2), from an Azeri ethnic group (AI 2.0), in the age category 25-34 years (AI 1.5), married (AI 1.5), or practicing Islam (AI 1.5). Unwillingness to have more children was the most commonly cited reason for the abortion decision $(49.4 \%)$, followed by socioeconomic concerns $(22.0 \%)$ and desire to space out pregnancies $(18.1 \%)$. Health-related reasons were cited by only $7.5 \%$ as a leading motive for abortion.

Conclusion: Women with specific background characteristics are disproportionally affected by abortion and, thus, are in utmost need of support in successful birth planning. Desire to stop or space childbearing and socioeconomic challenges are the overriding motives for terminating unintended pregnancies. Planning and execution of effective family planning programs targeting those at greatest risk for abortion have the potential to reduce the burden of induced abortion in Georgia.

Keywords: induced abortion reason, Georgia, family planning

\section{Introduction}

Reproductive preferences, practices, and behaviors vary markedly across societies and countries. Georgia, a former Soviet republic, has practiced a rather austere approach toward sexual and reproductive health - a carryover from the Soviet system, infamous for its lack of support for family planning and high tolerance for pregnancy termination. ${ }^{1}$ Induced abortion, not contraception, was the core culturally accepted method of birth control in Georgia, ${ }^{2}$ resulting in the world's highest abortion estimate reported in 1999 by the first population-based Reproductive Health Survey (RHS). ${ }^{3}$ The influx of substantial international donor assistance reinforced by government support led to increased access to family planning services and an encouraging fall in abortion rates. ${ }^{4,5}$ Yet, some women in Georgia steadily prioritize abortion to realize their reproductive goals.

Identifying why women still resort to abortion and defining the subgroups of women disproportionately affected by abortion are vital to policy planning and reducing the burden of abortion problems in Georgia.
Correspondence: Ekaterine Pestvenidze Institute of Clinical Medicine, Rikshospitalet, Division of Women and Children, University of Oslo, 10 Jvania str, Tbilisi, 0179, Georgia Tel +995 59l 206030

Email ekapestvenidze@gmail.com $\mathrm{BY} \mathrm{NC}$ and incorporate the Creative Commons Attribution - Non Commercial (unported, v3.0) License (http://creativecommons.org/licenses/by-nc/3.0/). By accessing the work you
hereby accept the Terms. Non-commercial uses of the work are permitted without any further permission from Dove Medical Press Limited, provided the work is properly attributed. For permission hereby accept the Terms. Non-commercial uses of the work are permitted without any further permission from Dove Medic
for commercial use of this work, please see paragraphs 4.2 and 5 of our Terms (https://www.dovepress.com/terms.php). 
Many previous studies elsewhere have tried to provide sociodemographic portrait of the women obtaining abortion services, the principal motives guiding their decision to terminate pregnancies, ${ }^{6-18}$ and the supply (accessibility) and demand (demographic) factors affecting induced abortion rates. ${ }^{19}$ The findings are diverse and controversial, rooted in cultural, religious, social, and economic variations across and within nations. In addition, these studies have mostly been country specific, limited in geographic scope and, thus, not generalizable or applicable to the Georgian context with its unique reproductive health practices and norms shaped by its historical, social, and cultural background.

The present study is the first attempt to shed light on the women's motives for choosing to undergo abortions and to identify the sociodemographic subgroups with the highest abortion rates and, thus, in greatest need of support to reduce unintended pregnancies and enhance the ability for birth control.

\section{Materials and methods}

To obtain the most comprehensive and nationally representative information on induced abortion among women of reproductive age in Georgia, we utilized data from the population-based Georgian RHS 2010. ${ }^{5}$

The protocol for the secondary analysis of the survey data was reviewed and approved by independent ethics committees - the Health Research Union Institutional Review Board of Georgia (IRB00009520) and the Regional Committee for Medical and Health Research Ethics of Norway (2015/1351/REK).

The survey was carried out according to the ethical principles for medical research stipulated in the Declaration of Helsinki. All the women surveyed provided informed consent prior to interview and received a detailed description of the study objectives and protocol.

\section{Study population/sample size}

Data on induced abortion were derived from the RHS study, which collected information from a nationally representative sample of women of reproductive age between 15 and 44 years through face-to-face in-depth interviews. Of the 6,356 eligible respondents, 6,292 women were successfully interviewed, yielding a response rate of $99 \%$. Further details on the original study methodology (survey design, sampling, questionnaire development, recruitment process, data collection, processing, and analysis) have been described elsewhere. ${ }^{5}$

The present study targeted women of reproductive age who underwent induced abortions within 5 years prior to the interview (2005-2009). In line with published research, we assumed a mean for the prevalence of induced abortions of $40 \%$ among women of reproductive age (15-44 years old). ${ }^{4}$ The minimum sample size for making true inferences was determined to be 369 , based on $5 \%$ probability of a type I error and a precision of 0.05 .

\section{Variables and measurement}

The key sociodemographic and pregnancy history variables derived from the previous studies were assessed for investigation of the common characteristics of women undergoing abortions (Table 1). ${ }^{6-18}$ Dichotomous variables included employment, marital status, and residence. Categorical predictors comprised age, education, ethnicity, parity, religion, and wealth status variables.

The eight-group categorical variable - reason for abortion - was studied to understand the principal motives guiding Georgian women's decision to undergo the procedure.

In order to ensure a sufficient sample size within each group of interest, we recoded and united the subgroups within selected variables (ie, parity, age, education, marital status).

To minimize the likelihood of recall bias, we analyzed the data only on abortions performed within 5 years prior to the interview.

To build the multivariate logistic regression model, the categorical variable - reason for abortion - was transformed into the eight independent dichotomous variables for each reason separately.

Two independent reasons for abortion variables - "pregnancy was life or health threatening" and "risk of birth defects" - were combined into a broader and more inclusive variable, "health-related problems", to ensure enough numbers in each category for statistical analysis.

\section{Data analysis}

The study employed SPSS version 21.0 (IBM Corporation, Armonk, NY, USA) for the main statistical analysis.

\section{Subgroups of women with the highest abortion proportions}

We obtained the descriptive statistics (absolute numbers and percentages) of the socioeconomic and demographic characteristics for abortion patients and performed a comparative analysis with similar characteristics for all the women surveyed. Due to the absence of reliable national abortion statistics, it was impossible to estimate abortion rates across the subgroups of interest. Hence, we introduced an alternative measure - the abortion index (AI) - which expresses the relative abortion rate for the subgroups of women who have 
Table I Number and percent distribution of women with abortion and all women aged I5-44 by selected characteristics

\begin{tabular}{|c|c|c|c|c|}
\hline \multirow[t]{2}{*}{ Characteristics } & $\begin{array}{l}\text { Women with } \\
\text { abortion }(n)\end{array}$ & $\begin{array}{l}\text { Women with } \\
\text { abortion (\%) }\end{array}$ & $\begin{array}{l}\text { All women } \\
\text { aged I5-44 (n) }\end{array}$ & $\begin{array}{l}\text { All women } \\
\text { aged I5-44 (\%) }\end{array}$ \\
\hline & \multicolumn{2}{|l|}{$\mathrm{n}=\mathbf{2 , 0 5 4}$} & \multicolumn{2}{|l|}{$\mathrm{n}=6,292$} \\
\hline \multicolumn{5}{|l|}{ Age, years } \\
\hline $15-24$ & 226 & 11.0 & 1,960 & 31.2 \\
\hline $25-34$ & $\mathrm{I}, 188$ & 57.8 & 2,359 & 37.5 \\
\hline $35-44$ & 640 & 31.2 & 1,973 & 31.4 \\
\hline \multicolumn{5}{|l|}{ Residence } \\
\hline Urban & 768 & 37.4 & 2,975 & 47.3 \\
\hline Rural & 1,286 & 62.6 & 3,317 & 52.7 \\
\hline \multicolumn{5}{|l|}{ Education } \\
\hline Secondary incomplete & 456 & 22.2 & 1,330 & 21.1 \\
\hline Secondary complete & 668 & 32.5 & $\mathrm{I}, 568$ & 24.9 \\
\hline Professional college & 286 & 13.9 & 903 & 14.4 \\
\hline University & 644 & 31.4 & 2,491 & 39.6 \\
\hline \multicolumn{5}{|l|}{ Wealth quintile } \\
\hline Lowest & 419 & 20.4 & 1,093 & 17.4 \\
\hline Second & 504 & 24.5 & $\mathrm{I}, 385$ & 22.0 \\
\hline Middle & 506 & 24.6 & $1,4 \mid 3$ & 22.5 \\
\hline Fourth & 282 & 13.7 & I,037 & 16.5 \\
\hline Highest & 343 & 16.7 & 1,364 & 21.7 \\
\hline \multicolumn{5}{|l|}{ Ethnicity } \\
\hline Georgian & $\mathrm{I}, 66 \mathrm{I}$ & 80.9 & 5,488 & 87.2 \\
\hline Azeri & 181 & 8.8 & 276 & 4.4 \\
\hline Armenian & $|4|$ & 6.9 & 364 & 5.8 \\
\hline Other & 71 & 3.5 & 164 & 2.6 \\
\hline \multicolumn{5}{|l|}{ Religion } \\
\hline Georgian orthodox & 1,609 & 78.3 & 5,297 & 84.2 \\
\hline Other orthodox & 140 & 6.8 & 337 & 5.4 \\
\hline Muslim & 264 & 12.9 & 524 & 8.3 \\
\hline Other & 26 & 1.3 & 101 & 1.6 \\
\hline No religion & 15 & 0.7 & 33 & 0.5 \\
\hline \multicolumn{5}{|l|}{ Marital status } \\
\hline Married & 1,988 & 96.8 & 4,098 & 65.1 \\
\hline Not currently married & 66 & 3.2 & 2,194 & 34.9 \\
\hline \multicolumn{5}{|l|}{ Employment } \\
\hline Employed & 360 & 17.5 & 1,410 & 22.4 \\
\hline Unemployed & I,694 & 82.5 & 4,882 & 77.6 \\
\hline \multicolumn{5}{|l|}{ Parity } \\
\hline$\leq 1$ & 330 & 16.1 & 3,508 & 55.8 \\
\hline 2 & 1,223 & 59.5 & 2,006 & 31.9 \\
\hline 3 & 376 & 18.3 & 605 & 9.6 \\
\hline$\geq 4$ & 125 & 6.1 & 173 & 2.7 \\
\hline
\end{tabular}

undergone abortions in comparison with similar subgroups from the study sample of 6,292 nationally representative women of reproductive age.

The representativeness of the study sample was verified by comparing the survey results of the sociodemographic subgroups with the national statistics data for the same subgroups. ${ }^{20}$ Of the characteristics available for comparison, the results were within $<1 \%$ difference.

To calculate the AI, we divided the proportion of women undergoing abortions within each subgroup by the 
proportion of all women of reproductive age interviewed from the same subgroup. An AI equal to one (AI=1.0) meant that there was no difference between the women who had undergone abortion in the specific subgroup and women from the same subgroup in general study sample. An AI of more than one $(\mathrm{AI}>1.0)$ indicated overrepresentation of a specific subgroup of women who had undergone abortion compared to the study population. By contrast, an AI less than one $(\mathrm{AI}<1.0)$ showed underrepresentation of the particular subgroup of women who had undergone abortion compared to the study population.

\section{Reasons for abortion}

We performed a descriptive analysis of the reasons for pregnancy termination and assessed the statistical significance of differences in proportions using the chi-squared test for categorical variables.

We applied multivariate binary logistic regression analyses to study the sociodemographic predictors of the four principal reasons guiding women's decision to undergo an abortion.

\section{Results}

\section{Subgroups of women with the highest proportion of abortions}

In all, 2,054 abortions were procured by women interviewed within 5 years prior to the interview. Table 1 demonstrates the distribution of women who underwent abortions and women in the reference category (all women interviewed who were of reproductive age 15-44) across major socioeconomic, demographic, and pregnancy history subgroups. Figure 1 shows the AI (the relative abortion rate) for the same subgroups of women.

In the age category, women aged 25-34 years accounted for the largest share of abortions (57.8\%), followed by women aged 35-44 years $(31.2 \%)$ and then by the youngest group (those aged 15-24 years [11.0\%]). The distribution of the age subgroups among women of reproductive age in the general population is somewhat different. According to the national statistics data, women in the age category of 25-34 years represent $36 \%$ of all women of reproductive age, followed by women in the oldest age group, with $32.8 \%$, and then the youngest group, with $31.2 \%$ representation. ${ }^{20}$ The AI analysis supports the findings from descriptive data and shows that women aged 25-34 years are overrepresented in the abortion group (AI 1.5) when compared to the general study sample. The disparity was not pronounced among women who had undergone abortions and the reference group in the age category 35-44 (AI 1.0). In contrast, the youngest women
(15-24 years) showed the lowest relative abortion rate among the age groups evaluated (AI 0.4).

Although Georgian women accounted for $80.9 \%$ of all abortions performed in the study population, their relative abortion rate (AI 0.9) was well below that of other ethnic minorities. The leading ethnic group in obtaining abortions was represented by Azeri women, with an AI of 2.0, twice that of Georgian women.

Ethnic and religious subgroups are closely interrelated in Georgia, and thus document similar patterns. Thus, Islam, commonly associated with the Azeri population, was dominant in the relative abortion rates (AI 1.5), ahead of the orthodox religion practiced predominantly by Georgian women (AI 0.9).

The striking difference was in the relative abortion rates of married and currently unmarried women, rooted in the cultural specifics of traditional Georgian society which is highly resistant to extramarital sexual relationships. Only 66 abortions were reported by currently unmarried women, constituting $3.2 \%$ of all abortions performed in contrast to $96.6 \%$ reported by married women. Consequently, the AI in the unmarried subgroup was very small at 0.1 , whereas that for the married group was 1.5 .

The number of living children was found in the survey to be progressively proportional to rise in the AI. The lowest relative abortion rate was documented among groups of women with one child and less (AI 0.3); the rate increased with two to three children (AI 1.9) and was the highest among women with four or more children (AI 2.2).

The distribution of women undergoing abortion according to educational attainment was somewhat different from that of the general study sample. Women with completed secondary education had an elevated representation in the abortion group (AI 1.3) in contrast with university-educated women (AI 0.8).

Income differential was trivial among abortion subgroups and the general study sample. The relative abortion rate was highest among poor (AI 1.2) and lowest among high-income groups (AI 0.8).

Rural women were slightly overrepresented in the abortion group vis-à-vis their urban counterparts (AI 1.2).

The distribution of women undergoing abortion by employment status was almost proportional to that of the overall study sample, the difference being employed women were slightly underrepresented in the abortion group (AI 0.8).

Thus, women with the highest representation in the abortion group compared to the general study sample were those with two and more children, representing the Azeri ethnic group, in the age group 25-34, married, or practicing Islam (Figure 1). 


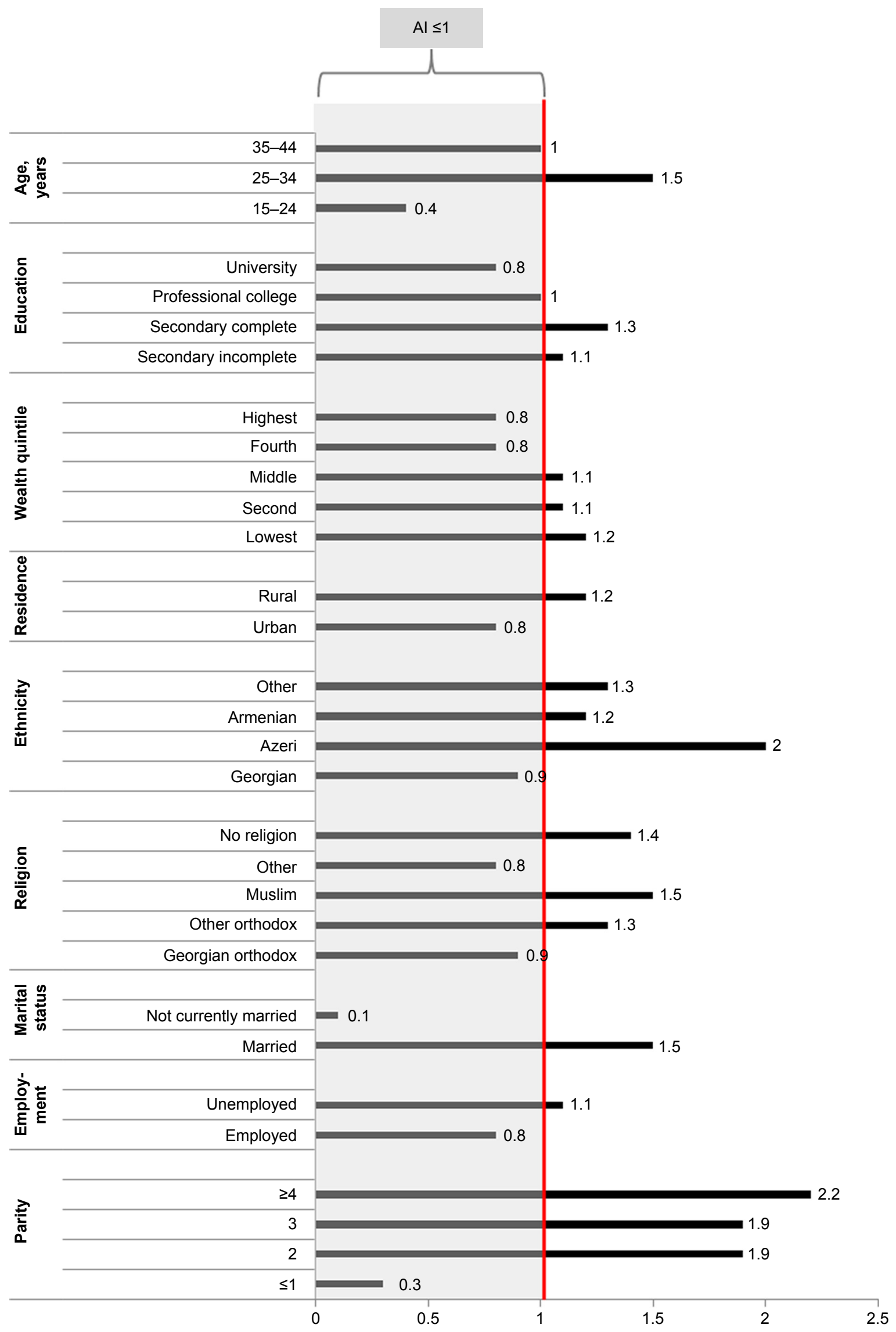

Figure I Al by selected sociodemographic characteristics. Abbreviation: Al, abortion index. 


\section{Reasons for abortion}

The frequency and distribution by percentage of women's reasons to undergo abortion are presented in Table 2. For the 2,054 abortions performed, the paramount motive for pregnancy termination was unwillingness to have more children, reported by a plurality of women (49.4\%). Socioeconomic concerns were the second most frequently cited reason guiding women to an abortion decision (22.0\%), followed by desire to space out pregnancies (18.1\%). Health-related reasons were reported by $7.5 \%$ of women as a leading motive for abortion. Other categories of reasons were minimally represented in women's responses and constituted $<5 \%$ of all answers obtained. The observed differences in proportions of reported reasons were statistically significant $(P<0.001)$.

\section{Sociodemographic characteristics related to reasons for abortion}

We evaluated the four most frequently cited reasons for seeking abortion services according to women's sociodemographic characteristics, applying multivariate logistic regression analyses (Table $3 \mathrm{~A}$ and $\mathrm{B}$ ).

Unwillingness to have more children was the main reason influencing women's abortion decision and was shown to be associated with their age, education, wealth status, ethnicity, marital status, employment, parity, and number of abortions. Women identifying a "desire to end childbearing" as the most important reason were significantly more likely to be older (OR 1.49-2.67), wealthier (OR 1.36-1.99), employed (OR 2.35), members of the Azeri or Armenian ethnic group (OR 2.26-3.73), parent to two or more children (OR 2.63-4.45), and likely to experience four or more abortions (OR 1.87); they were less likely to be married (OR 0.73) and to have a university education (OR 0.55 ) rather than a secondary or incomplete school education.

Women reporting socioeconomic concerns as the overriding reason for abortion were significantly more likely to be older than younger (OR 1.74-2.01), currently in marriage (OR 1.70), and to experience more than one abortion (OR 1.38-1.44); they were less likely to be wealthy (OR 0.31-0.60) and to be Azeri rather than Georgian (OR 0.17).

A clear association emerged between women motivating their abortion by the desire to space out their pregnancies and age, education, wealth status, and parity. Women citing a desire to postpone their next pregnancy were more likely to have a higher education (OR 2.13-3.70) and to be in the second wealth quintile than in the lowest (OR 1.56); they were less likely to be in the older age categories (OR 0.08-0.38) and to have two or three children (OR 0.28-0.46).

Significant predictors of reporting health problems as the predominant reason for abortion were place of residence, wealth status, ethnicity, number of children, and number of previous abortions (Table 3B). Women citing health problems as a principal motive for pregnancy termination were more likely to reside in an urban than a rural area (OR 1.95 ) and to have had previous abortions (OR 1.91-2.63), and were less likely to have other children (OR 0.25-0.34), to be wealthy (OR 0.25-0.43), and to be Armenian or Azeri than Georgian (OR 0.04-0.33).

\section{Discussion}

\section{Subgroups of women with the highest proportion of abortions}

Induced pregnancy terminations occur in virtually all demographic and socioeconomic subgroups, reinforcing the universality of the abortion phenomenon. Yet, they are disproportionally distributed across specific background characteristics.

Women aged 25-34 years, married, representing an Azeri ethnic group, practicing Islam, or having two or more children were found to be more likely to undergo an abortion procedure in Georgia.

Like other studies, ours documented the highest concentration of women having abortions around the middle

Table 2 Reasons for abortion

\begin{tabular}{|l|l|l|l|l|}
\hline Reasons for abortion & Frequency $\mathbf{( n = 2 , 0 5 4 )}$ & Percent (\%) & $\chi^{2}$ & P-value \\
\hline Pregnancy was life or health threatening & 97 & 4.7 & \\
\hline Risk of birth defects & 57 & 2.8 & \\
\hline Socioeconomic reasons & 452 & 22.0 \\
\hline Did not want more children & 1,015 & 49.4 & \\
\hline Spacing next pregnancy & 372 & 18.1 & \\
\hline Partner did not want children & 21 & 1.0 & \\
\hline Did not have a partner/husband & 2 & 0.1 & \\
\hline Other & 38 & 1.9 & \\
\hline
\end{tabular}


Table 3 Multivariate logistic regression analysis of reasons for abortion by women's characteristics

\begin{tabular}{|c|c|c|c|c|c|c|c|c|}
\hline \multirow{2}{*}{$\begin{array}{l}\text { (A) Characteristics } \\
\text { Age, years }\end{array}$} & \multicolumn{4}{|c|}{ Did not want more children } & \multicolumn{4}{|c|}{ Socioeconomic reasons } \\
\hline & OR & \multicolumn{2}{|c|}{$95 \% \mathrm{Cl}$} & $P$-value & OR & \multicolumn{2}{|c|}{$95 \% \mathrm{Cl}$} & $P$-value \\
\hline \multicolumn{9}{|l|}{ 15-24 (ref) } \\
\hline $25-34$ & 1.489 & 1.041 & 2.129 & 0.029 & 1.739 & 1.135 & 2.665 & 0.011 \\
\hline $35-44$ & 2.665 & 1.811 & 3.921 & $<0.001$ & 2.010 & 1.269 & 3.184 & 0.003 \\
\hline \multicolumn{9}{|l|}{ Residence } \\
\hline \multicolumn{9}{|l|}{ Rural (ref) } \\
\hline Urban & 1.012 & 0.756 & 1.356 & 0.935 & 0.753 & 0.537 & 1.056 & 0.100 \\
\hline \multicolumn{9}{|l|}{ Education } \\
\hline \multicolumn{9}{|c|}{ Secondary incomplete (ref) } \\
\hline Secondary complete & 0.675 & 0.511 & 0.891 & 0.006 & 0.999 & 0.731 & 1.365 & 0.995 \\
\hline Professional college & 0.603 & 0.425 & 0.855 & 0.005 & 0.819 & 0.549 & 1.221 & 0.327 \\
\hline University & 0.551 & 0.400 & 0.759 & $<0.001$ & 0.854 & 0.594 & 1.229 & 0.396 \\
\hline \multicolumn{9}{|l|}{ Wealth quintile } \\
\hline \multicolumn{9}{|l|}{ Lowest (ref) } \\
\hline Second & 1.358 & 1.010 & 1.825 & 0.043 & 0.603 & 0.438 & 0.831 & 0.002 \\
\hline Middle & 1.991 & 1.464 & 2.709 & $<0.001$ & 0.401 & 0.284 & 0.566 & $<0.001$ \\
\hline Fourth & 1.733 & 1.138 & 2.639 & 0.010 & 0.458 & 0.288 & 0.729 & 0.001 \\
\hline Highest & 1.927 & 1.263 & 2.940 & 0.002 & 0.305 & 0.188 & 0.495 & $<0.001$ \\
\hline \multicolumn{9}{|l|}{ Ethnicity } \\
\hline \multicolumn{9}{|l|}{ Georgian (ref) } \\
\hline Azeri & 3.727 & 2.023 & 6.866 & $<0.001$ & 0.165 & 0.068 & 0.397 & $<0.001$ \\
\hline Armenian & 2.261 & 1.050 & 4.869 & 0.037 & 0.483 & 0.213 & 1.094 & 0.081 \\
\hline Other & 0.571 & 0.319 & 1.024 & 0.060 & 1.779 & 0.964 & 3.283 & 0.065 \\
\hline \multicolumn{9}{|l|}{ Religion } \\
\hline \multicolumn{9}{|l|}{ Georgian orthodox (ref) } \\
\hline Other orthodox & 0.915 & 0.430 & 1.950 & 0.818 & 1.899 & 0.856 & 4.211 & 0.114 \\
\hline Muslim & 1.384 & 0.852 & 2.247 & 0.190 & 0.697 & 0.388 & 1.252 & 0.227 \\
\hline Other & 0.120 & 0.039 & 0.368 & $<0.001$ & 9.031 & 3.205 & 25.453 & $<0.001$ \\
\hline No religion & 0.995 & 0.296 & 3.346 & 0.994 & 1.642 & 0.481 & 5.607 & 0.429 \\
\hline \multicolumn{9}{|l|}{ Marital status } \\
\hline Married (ref) & & & & & & & & \\
\hline Not currently married & 0.732 & 0.560 & 0.956 & 0.022 & 1.695 & 1.212 & 2.369 & 0.002 \\
\hline Employment & & & & & & & & \\
\hline Employed (ref) & & & & & & & & \\
\hline Unemployed & 2.349 & 1.340 & 4.118 & 0.003 & 0.523 & 0.239 & 1.147 & 0.106 \\
\hline Number of induced & & & & & & & & \\
\hline I (ref) & & & & & & & & \\
\hline 2 & 1.112 & 0.863 & 1.433 & 0.410 & 1.378 & 1.026 & 1.850 & 0.063 \\
\hline 3 & 1.294 & 0.970 & 1.725 & 0.080 & 1.435 & 1.028 & 2.004 & 0.064 \\
\hline$\geq 4$ & 1.866 & 1.431 & 2.433 & $<0.001$ & 1.203 & 0.883 & 1.641 & 0.242 \\
\hline Parity & & & & & & & & \\
\hline$\leq \mathrm{I}$ (ref) & & & & & & & & \\
\hline 2 & 3.017 & 2.203 & 4.131 & $<0.001$ & 1.241 & $0.88 I$ & 1.748 & 0.216 \\
\hline 3 & 4.453 & 3.056 & 6.490 & $<0.001$ & 0.784 & $0.5 \mathrm{II}$ & 1.203 & 0.265 \\
\hline$\geq 4$ & 2.631 & 1.582 & 4.375 & $<0.001$ & 0.844 & 0.470 & 1.514 & 0.569 \\
\hline
\end{tabular}


Table 3 (Continued)

\begin{tabular}{|c|c|c|c|c|c|c|c|c|}
\hline \multirow{3}{*}{$\begin{array}{l}\text { (B) Characteristics } \\
\text { Age, years }\end{array}$} & \multicolumn{4}{|c|}{ Spacing next pregnancy } & \multicolumn{4}{|c|}{ Health-related reason } \\
\hline & \multirow[t]{2}{*}{ OR } & \multicolumn{2}{|c|}{$95 \% \mathrm{Cl}$} & \multirow[t]{2}{*}{$P$-value } & \multirow[t]{2}{*}{ OR } & \multicolumn{2}{|c|}{$95 \% \mathrm{Cl}$} & \multirow[t]{2}{*}{$P$-value } \\
\hline & & & & & & & & \\
\hline \multicolumn{9}{|l|}{ 15-24 (ref) } \\
\hline $25-34$ & 0.383 & 0.268 & 0.546 & $<0.001$ & 0.969 & 0.522 & 1.796 & 0.919 \\
\hline $35-44$ & 0.083 & 0.051 & 0.135 & $<0.001$ & 1.073 & 0.711 & 1.619 & 0.738 \\
\hline \multicolumn{9}{|l|}{ Residence } \\
\hline \multicolumn{9}{|l|}{ Rural (ref) } \\
\hline Urban & 0.923 & 0.638 & 1.335 & 0.670 & 1.953 & 1.112 & 3.429 & 0.020 \\
\hline \multicolumn{9}{|l|}{ Education } \\
\hline \multicolumn{9}{|c|}{ Secondary incomplete (ref) } \\
\hline Secondary complete & 2.128 & 1.400 & 3.233 & $<0.001$ & 0.735 & 0.386 & 1.399 & 0.348 \\
\hline Professional college & 3.307 & 2.003 & 5.458 & $<0.001$ & 1.247 & 0.794 & 1.958 & 0.337 \\
\hline University & 3.703 & 2.334 & 5.874 & $<0.001$ & 0.912 & 0.518 & 1.608 & 0.751 \\
\hline \multicolumn{9}{|l|}{ Wealth quintile } \\
\hline \multicolumn{9}{|l|}{ Lowest (ref) } \\
\hline Second & 1.556 & 1.042 & 2.324 & 0.031 & 0.322 & 0.154 & 0.672 & 0.003 \\
\hline Middle & 1.217 & 0.802 & 1.846 & 0.356 & 0.255 & 0.125 & 0.523 & $<0.001$ \\
\hline Fourth & 0.915 & 0.528 & 1.586 & 0.752 & 0.248 & 0.126 & 0.489 & $<0.001$ \\
\hline Highest & 0.626 & 0.356 & 1.100 & 0.103 & 0.728 & 0.433 & 1.223 & 0.230 \\
\hline \multicolumn{9}{|l|}{ Ethnicity } \\
\hline \multicolumn{9}{|l|}{ Georgian (ref) } \\
\hline Azeri & 0.725 & 0.302 & 1.741 & 0.472 & 0.333 & 0.138 & 0.801 & 0.014 \\
\hline Armenian & 0.406 & 0.126 & 1.314 & 0.132 & 0.044 & 0.007 & 0.263 & 0.001 \\
\hline Other & 0.656 & 0.276 & 1.557 & 0.339 & 0.207 & 0.035 & 1.234 & 0.084 \\
\hline \multicolumn{9}{|l|}{ Religion } \\
\hline \multicolumn{9}{|l|}{ Georgian orthodox (ref) } \\
\hline Other orthodox & 0.680 & 0.209 & 2.210 & 0.521 & 0.691 & 0.145 & 3.285 & 0.642 \\
\hline Muslim & 0.796 & 0.397 & 1.595 & 0.520 & 0.132 & 0.016 & 1.075 & 0.058 \\
\hline Other & 1.219 & 0.249 & 5.967 & 0.807 & 1.248 & 0.228 & 6.830 & 0.798 \\
\hline No religion & 0.544 & 0.104 & 2.828 & 0.469 & 0.567 & 0.044 & 7.375 & 0.664 \\
\hline \multicolumn{9}{|l|}{ Marital status } \\
\hline Married (ref) & & & & & & & & \\
\hline Not currently married & 1.282 & 0.896 & 1.835 & 0.174 & 0.310 & 0.089 & 1.076 & 0.065 \\
\hline Employment & & & & & & & & \\
\hline Employed (ref) & & & & & & & & \\
\hline Unemployed & 0.512 & 0.227 & 1.158 & 0.108 & 0.688 & 0.439 & 1.078 & 0.103 \\
\hline Number of induced a & & & & & & & & \\
\hline I (ref) & & & & & & & & \\
\hline 2 & 0.866 & 0.633 & 1.184 & 0.367 & 2.630 & 1.549 & 4.465 & $<.001$ \\
\hline 3 & 0.689 & 0.466 & 1.018 & 0.062 & 1.910 & 1.089 & 3.349 & 0.024 \\
\hline$\geq 4$ & 0.592 & 0.415 & 0.846 & 0.064 & 0.723 & 0.342 & 1.528 & 0.395 \\
\hline Parity & & & & & & & & \\
\hline$\leq \mathrm{I}$ (ref) & & & & & & & & \\
\hline 2 & 0.458 & 0.335 & 0.627 & $<0.001$ & 0.338 & 0.221 & 0.517 & $<0.001$ \\
\hline 3 & 0.283 & 0.174 & 0.460 & $<0.001$ & 0.426 & 0.240 & 0.756 & 0.004 \\
\hline$\geq 4$ & 0.833 & 0.433 & 1.605 & 0.586 & 0.256 & $0.08 I$ & 0.809 & 0.020 \\
\hline
\end{tabular}

Abbreviation: Ref, reference group. 
age category (25-34 years). ${ }^{67,18,21}$ The observed pattern was probably driven by the higher likelihood of members of this age group being married, fecund, and sexually active. In addition, Georgian women, expected to begin bearing children soon after marriage, are likely to have at least one child in this age range, and hence need to space out or limit their childbearing. The abortion distribution pattern by age group in Georgia follows an inverted U shape: the lowest abortion proportion in the youngest age category is followed by a sharp increase in the middle age category and a subsequent fall in the oldest age group. The findings of the study contrast with those from African countries, where the youngest and nulliparous women are disproportionally affected by abortion, which is likely related to the early initiation of sexual life and limited access to family planning education and contraceptive services due to associated social stigma or scarcity of resources. ${ }^{7,12}$

Pronounced interrelated ethnic and religious disparities in relative abortion rates were evidenced by the study. Azeri women, who mostly adhere to Islam, showed a disproportionally high representation among women choosing to undergo abortions, when compared to Georgians. The observed disparity and its magnitude probably reflect cultural and religious specifics of the Azeri and Muslim population, who are resistant to family planning services and supportive of early marriages and early initiation of sexual life. ${ }^{22}$

The study showed a highly disproportional representation of women undergoing abortion by marital status. Currently unmarried women constituted only $3.2 \%$ of all abortions performed, yielding an AI of 0.1. Deeply ingrained cultural and traditional norms, as well as the predominance of a doctrine discouraging extramarital sexual activity, are likely responsible for the unusual pattern observed, which fundamentally conflicts with the findings of other studies. ${ }^{6,7,9,13,17,23-26}$ In a study by Jones et al, the proportion of US women having an abortion who had never been married was as high as $67 \%$. Bankole et al showed that among 40 countries studied, 23 reported a higher proportion of abortions among married women and 17 among unmarried women. ${ }^{7}$ Interestingly, married women make up a higher proportion of abortions in developing countries and unmarried women in developed countries. ${ }^{7}$ Even though currently unmarried women in developed countries are less likely to become pregnant, once pregnant, a much higher proportion of their pregnancies end in abortion compared to pregnancies of married women.

As expected, the study found the likelihood of abortions to increase incrementally with higher number of children, suggesting that women in Georgia use abortion to space out pregnancies or to stop childbearing, rather than to delay a family foundation. The observed pattern is consistent across all available studies s,-23,27 $^{7}$ and is justified by our study findings on the reasons for abortion. It showed that the paramount motive for pregnancy termination is to end childbearing, commonly accomplished in Georgia after two or three children.

The study found a relatively less pronounced overrepresentation of low-educated, low-income, and rural women in the abortion group. Limited education and income are classic factors known to be associated with abortion. . $^{8,911,23,28}$ We found a somewhat elevated abortion representation among women with secondary education and those in the low-wealth quintile. Economically disadvantaged women with less schooling experience more challenges to comprehending the importance of avoiding unintended pregnancies and in finding the resources needed to obtain access to and use contraceptive services. This contrasted with the findings of other studies documenting a disproportionate share of induced abortion among higher-educated and wealthier women, who may have stronger motivations for a smaller family size and, thus, frequently utilize abortion services to limit childbearing. 6,7

Residing in a rural area was also found to be associated with slightly elevated relative abortion rates, probably reflective of limited access to and use of family planning services by rural dwellers in Georgia. While urban women have better access to contraceptive services, they presumably have better access to abortion services as well, which likely explains the higher abortion rates observed among urban women in some other countries. ${ }^{6,7}$

\section{Reasons for abortion}

Women seek to terminate a pregnancy for a variety of reasons, driven commonly by their unique socioeconomic characteristics. In Georgia, the predominant motive guiding a woman's decision to seek an abortion is a desire to cease childbearing, observed in the older age category of women and among women with two or more children. Older women and those with two or more children had likely accomplished their desired family size and, thus, had a greater need to stop reproducing.

The findings echo those of previous studies. ${ }^{29,30}$ Yet, a desire to cease childbearing was a less commonly cited reason for abortion among women in Latin American countries and the US - likely attributable to high utilization of permanent family planning methods (ie, sterilization) 
in these geographic regions, once the desired number of children was achieved..$^{30}$

The second most frequently cited reason for pregnancy termination was economic instability, consistently found to be among the predominant abortion motivators in many other studies. ${ }^{29-34}$ In this decision, women are commonly guided by broader concepts of motherhood, responsibility, and the desire to be a good parent. They believe that a child deserves to be raised in a financially stable and secure environment, which they could not afford to provide under the current circumstances. ${ }^{32}$ As expected, women citing financial hardship as the overriding reason for abortion were mostly disadvantaged and older. Older women are predominantly governed by a greater sense of responsibility to their existing children or other dependents and, thus, are more likely to terminate a pregnancy upon facing financial constraints. ${ }^{33}$

Spacing out pregnancies was also underscored as a prevailing motive for pregnancy termination by a large proportion of women who underwent abortions, suggesting that women in Georgia still experience considerable difficulties in successful birth planning. This finding is in line with the large body of evidence collected to date. A study by Bankole et al showed that the desire to postpone or cease reproduction was identified as a leading motive for abortion in 20 out of 27 countries studied. $^{7}$

Only a small proportion of Georgian women decided to end their pregnancy because of health-related problems, either maternal or fetal. This reason does not feature prominently in previous studies, except those in sub-Saharan Africa and South Asia, where health-related issues are identified as a principal motive for abortion. In these countries, pronounced socioeconomic constraints and close birth spacing were likely responsible for the relatively high prevalence of maternal-fetal health problems. ${ }^{30}$

\section{Limitations}

Several limitations should be taken into consideration before interpreting the findings of this study. As with any study using data extracted through a self-reported survey, this one may have inherent biases, leading to either underreporting or overreporting. Strong cultural and moralistic norms governing sexual and reproductive behaviors in Georgia, as well as the social unacceptability of extramarital sexual relationships, may prompt unmarried women to underreport abortion experiences, resulting in a social desirability bias. To minimize the possibility of such bias, absolute confidentiality and privacy were preserved during each interview.

The other shortcoming of the study lies in its exclusive focus on a single predominant reason for pregnancy termination. The complex motives for abortion may not have been fully captured in cases where several factors simultaneously contributed to women's decision to terminate their pregnancy. More research using an in-depth investigation of the multiple reasons for abortion could be useful in enhancing our understanding of the multidimensional factors shaping women's decision to terminate pregnancy.

\section{Conclusion}

Women from all socioeconomic and demographic subgroups are the subjects to induced pregnancy termination. Yet, in Georgia, women with specific background characteristics those from ethnic and religious minorities, those in the middle age category, those who are married, and those with two or more children - are disproportionately affected by abortion, and are thus in greatest need of targeted support for successful birth planning.

The desire to cease or space out childbearing and socioeconomic challenges are the overriding reasons for pregnancy termination in Georgia. Better access to and use of long-lasting or permanent contraceptive methods among those who have accomplished the desired family size have the potential to reduce the burden of abortion. The predominance of socioeconomic concerns among abortion motives also reinforces the need for publicly supported family planning programs, specifically for the socially disadvantaged.

\section{Acknowledgments}

The authors express special appreciation to the National Center for Disease Control and Public Health of Georgia and the US Centers for Disease Control and Prevention for conducting the Reproductive Health Survey 2010 and for providing the survey data to the authors of the study for secondary analysis. The authors also thank Letten Foundation for providing financial support for the work.

\section{Author contributions}

Both authors contributed toward data analysis, drafting and critically revising the paper, gave final approval of the version to be published, and agree to be accountable for all aspects of the work.

\section{Disclosure}

The authors report no conflicts of interest in this work.

\section{References}

1. Antarsh L. The U.S.S.R. in transition: contraception and abortion. AVSC News. 1991;29(3):1-2.

2. Gotsadze T. United Nations Population Fund. Gap analysis of family planning services in Georgia. Final report; 2013. Available from: http:// en.calameo.com/books/000713529f5a20866905a. Accessed October 12, 2018 . 
3. Serbanescu F, Morris L, Nutsubidze N, Imnadze P, Shakh-Nazarova M. Reproductive health survey Georgia, 1999-2000. Final report; 2001. Available from: http://ghdx.healthdata.org/record/georgia-reproductivehealth-survey-1999-2000. Accessed July 16, 2018.

4. Serbanescu F, Imnadze P, Bokhua Z, Nutsubidze N. Reproductive health survey Georgia, 2005 Final report. Available from: http:/ ghdx.healthdata.org/record/georgia-reproductive-health-survey-2005. Accessed July 12, 2018.

5. Butsashvili M, Kandelaki G, Sturua L, Shakh-Nazarova M, Mebonia N, Avaliani N. Reproductive health survey Georgia, 2010. Final report; 2012. Available from: http:/hivhealthclearinghouse.unesco.org/sites/ default/files/resources/reproductive_health_survey_georgia_2010.pdf. Accessed July 20, 2018

6. Chae S, Desai S, Crowell M, Sedgh G, Singh S. Characteristics of women obtaining induced abortions in selected low- and middle-income countries. PLoS One. 2017;12(3):e0177149.

7. Bankole A, Singh S, Haas T. Characteristics of women who obtain induced abortion: a worldwide review. Int Fam Plan Perspect. 1999;25(2): $68-77$.

8. Regushevskaya E, Dubikaytis T, Laanpere M, et al. Risk factors for induced abortions in St Petersburg, Estonia and Finland. Results from surveys among women of reproductive age. Eur J Contracept Reprod Health Care. 2009;14(3):176-186.

9. Jones RK, Darroch JE, Henshaw SK. Patterns in the socioeconomic characteristics of women obtaining abortions in 2000-2001. Perspect Sex Reprod Health. 2002;34(5):226-235.

10. Henshaw SK, Silverman J. The characteristics and prior contraceptive use of U.S. abortion patients. Fam Plann Perspect. 1988;20(4):158-168.

11. Jerman J, Jones RK, Onda T. Characteristics of U.S. abortion patients in 2014 and changes since 2008, New York: Guttmacher Institute, 2016. Available from: https://www.guttmacher.org/report/characteristics-usabortion-patients-2014. Accessed October 12, 2018.

12. Adjei G, Enuameh Y, Asante KP, et al. Predictors of abortions in rural Ghana: a cross-sectional study. BMC Public Health. 2015;15:202.

13. Henshaw SK, Kost K. Abortion patients in 1994-1995: characteristics and contraceptive use. Fam Plann Perspect. 1996;28(4):140-147.

14. Söderberg H, Andersson C, Janzon L, Sjöberg NO. Socio-demographic characteristics of women requesting induced abortion. A cross-sectional study from the Municipality of Malmo, Sweden. Acta Obstet Gynecol Scand. 1993;72(5):365-368.

15. Henshaw SK, O'Reilly K. Characteristics of abortion patients in the United States, 1979 and 1980. Fam Plann Perspect. 1983;15(1): 5810-5816. Jan-Feb.

16. Henshaw SK. Characteristics of U.S. women having abortions, 1982-1983. Fam Plann Perspect. 1987;19(1):5-9.

17. Henshaw SK, Binkin NJ, Blaine E, Smith JC. A portrait of American women who obtain abortions. Fam Plann Perspect. 1985;17(2): 90-96.

18. Bettarini SS, D'Andrea SS. Induced abortion in Italy: levels, trends and characteristics. Fam Plann Perspect. 1996;28(6):267-271.
19. Gober P. Why abortion rates vary: a geographical examination of the supply of and demand for abortion services in the United States in 1988. Ann Assoc Am Geogr. 1994;84(2):230-250.

20. National Center for Disease Control and Public Health. Health care statistical yearbook 2015, Georgia. 2016. Available from: http://ncdc. ge/AttachedFiles/yearbook\%202016_53210b52-12da-4279-9f27f7a361c84c96.pdf. Accessed October 15, 2018.

21. Singh B, Meyers LA. Estimation of single-year-of-age counts of live births, fetal losses, abortions, and pregnant women for counties of Texas. BMC Res Notes. 2017;10(1):178.

22. United Nations Population Fund. Child marriage in Georgia. Report; 2014. Available from: https://eeca.unfpa.org/sites/default/files/pub-pdf/ unfpa\%20georgia\%20overview.pdf. Accessed October 12, 2018.

23. Rasch V, Gammeltoft T, Knudsen LB, Tobiassen C, Ginzel A, Kempf L. Induced abortion in Denmark: effect of socio-economic situation and country of birth. EurJ Public Health. 2008;18(2):144-149.

24. Rasch V, Wielandt H, Knudsen LB. Living conditions, contraceptive use and the choice of induced abortion among pregnant women in Denmark. Scand J Public Health. 2002;30(4):293-299.

25. Mirembe FM. A situation analysis of induced abortions in Uganda Afr J Fertil Sexual Reprod Heal. 1996;1(1):79-80.

26. Filicori M, Flamigni C. Epidemiology of voluntary abortion in the region of Emilia Romagna and in Italy. Acta Eur Fertil. 1980;11(2):157-165.

27. Yi S, Tuot S, Chhoun P, Pal K, Tith K, Brody C. Factors associated with induced abortion among female entertainment workers: a crosssectional study in Cambodia. BMJ Open. 2015;5(7):e007947.

28. Söderberg H, Andersson C, Janzon L, Sjöberg NO. Socio-demographic characteristics of women requesting induced abortion. A cross-sectional study from the municipality of Malmö, Sweden. Acta Obstet Gynecol Scand. 1993;72(5):365-368.

29. Chae S, Desai S, Crowell M, Sedgh G. Reasons why women have induced abortions: a synthesis of findings from 14 countries. Contraception. 2017;96(4):233-241.

30. Bankole A, Singh S, Haas T. Reasons why women have induced abortions: evidence from 27 countries. Int Fam Plan Perspect. 1998;24(3): $117-152$.

31. Kirkman M, Rosenthal D, Mallett S, Rowe H, Hardiman A. Reasons women give for contemplating or undergoing abortion: a qualitative investigation in Victoria, Australia. Sex Reprod Healthc. 2010;1(4): 149-155.

32. Jones RK, Frohwirth LF, Ann M. "I would want to give my child, like, everything in the world". How issues of motherhood influence women who have abortions. J Fam Issues. 2008;29(1):79-99.

33. Finer LB, Frohwirth LF, Dauphinee LA, Singh S, Moore AM. Reasons U.S. women have abortions: quantitative and qualitative perspectives. Perspect Sex Reprod Health. 2005;37(3):110-118.

34. Larsson M, Aneblom G, Odlind V, Tydén T. Reasons for pregnancy termination, contraceptive habits and contraceptive failure among Swedish women requesting an early pregnancy termination. Acta Obstet Gynecol Scand. 2002;81(1):64-71.
International Journal of Women's Health

\section{Publish your work in this journal}

The International Journal of Women's Health is an international, peerreviewed open-access journal publishing original research, reports, editorials, reviews and commentaries on all aspects of women's healthcare including gynecology, obstetrics, and breast cancer. The manuscript management system is completely online and includes

\section{Dovepress}

a very quick and fair peer-review system, which is all easy to use. Visit http://www.dovepress.com/testimonials.php to read real quotes from published authors. 